\title{
Untangling the natural history of cerebral arteriovenous malformations
}

\author{
David J Werring (i), ${ }^{1}$ Rustam Al-Shahi Salman²
}

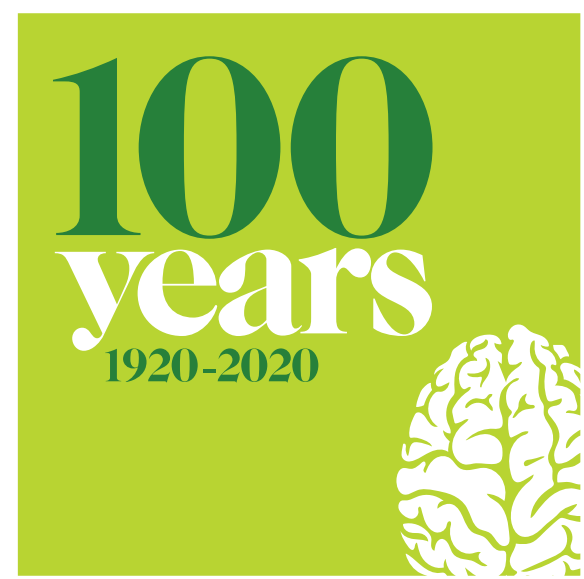

This landmark 1986 Journal of Neurology, Neurosurgery, and Psychiatry (JNNP) paper showed that previous bleeding from an arteriovenous malformation (AVM) is a key predictor of intracranial haemorrhage

AVMs have been recognised for millennia yet continue to fascinate and stimulate debate. AVMs consist of tangles of highflow, abnormally dilated non-nutritive vessels (termed the nidus) connecting feeding arteries with draining veins directly without the normal intervening capillary bed. The most feared complication of AVMs is bleeding into the brain substance (intracerebral haemorrhage) or subarachnoid space, which, owing to the high blood flow, can sometimes be severe. This bleeding risk is important because AVMs account for about onethird of intracerebral haemorrhages in young adults. ${ }^{1}$ Accurate understanding of the untreated clinical course of AVMs (particularly for intracranial bleeding risk, but also for epileptic seizures, death and neurological disability) is critical to counselling patients and informing any attempt at evaluating therapy. Yet,

\footnotetext{
${ }^{1}$ Stroke Research Centre, UCL Queen Square Institute of Neurology, London, UK

${ }^{2}$ Centre for Clinical Brain Sciences, University of Edinburgh, Edinburgh, UK
}

Correspondence to Professor David J Werring, Stroke Research Centre, UCL Institute of Neurology, London WC1B 5EH, UK; d.werring@ucl.ac.uk
Arteriovenous malformations of the brain: naturalhistory in unoperated patients.

Authors: Crawford PM, West CR, Chadwick DW, et al

Year Published: 1986

Number of times cited: 848

from the very first descriptions of AVMs and the origins of neurosurgery, surgical intervention began—no doubt hastened by the development of cerebral angiography in 1927-well before information on AVM outcomes was available. AVMs were then—and indeed, are still—among neurosurgery's greatest technical operative challenges. Moreover, the stakes are high because, balanced against the risk of AVM haemorrhage, surgical intervention also carries significant morbidity. Nevertheless, it became an article of neurosurgical faith that to operate was better than not to do $\mathrm{so}^{2}$; many studies of AVMs investigated the effects of surgery-sometimes demonstrating acceptable morbidity and survival ${ }^{3}$ - rather than their untreated clinical course. The first stereotactic radiosurgery, an important additional and less invasive treatment modality, was reported in $1970 .{ }^{4}$ However, the lack of controlled trials meant that the central dilemmas of whether, when and how to intervene in a patient with an AVM persisted for many years (and indeed continue to do so).

Understanding outcomes for untreated AVMs is difficult, typically due to small and selected cohorts, low event rates and short follow-up duration of untreated AVMs before treatment. The paper by Crawford et al, published in the JNNP in $1986,{ }^{5}$ was the first major study of the long-term clinical course of medically managed AVMs. This landmark paper made important observations about AVM natural history that have subsequently been confirmed and have informed much subsequent research. There are several remarkable features of this observational study. First, the authors included 343 patients with AVMs, of whom 217 were managed without neurosurgery; this large cohort size, in comparison to previous studies (and indeed compared with many more recent studies), was important in providing reasonably precise estimates for the rates of outcome events. Second, due to referral patterns into the Walton Centre, this was effectively a 'populationbased' study from a defined region of the UK (Merseyside, Clwyd, Gwynedd, parts of Cheshire, Lancashire and the Isle of Man), avoiding major selection bias. Third, study recruitment started between 1941 and 1948, providing several decades of follow-up data on long-term outcomes (median 9 years, maximum 35 years). Fourth, the untreated patients were broadly similar to those who were treated surgically, apart from an excess of left hemisphere and deeper or posterior lesions treated conservatively (probably because lesions at these sites are more difficult to safely access surgically); this suggests that the findings are reasonably generalisable to the population of people with untreated AVMs.

This study described the natural history of intracranial bleeding, epilepsy, neurological deficits and death. Over $50 \%$ of the patients included were less than 30 years old. The key findings were that a history of previous bleeding from the AVM and older age are predictive of intracranial bleeding risk over a long-term follow-up. If a patient had presented with haemorrhage, the 20-year risk of recurrent haemorrhage was $51 \%$, compared with a risk of $33 \%$ for patients with unruptured AVMs. The risk of haemorrhage for those over 60 years was $89 \%$ over 9 years, compared with $15 \%$ for those aged $20-29$ years. These findings have stood the test of time: a 2014 meta-analysis of cohort studies addressing the same question in over 2500 patients confirmed the predictive value of previous haemorrhage and age, but did not identify any other new predictors. ${ }^{6}$ These features remain a cornerstone of clinical decision-making regarding intervention for AVMs: surgery or other approaches (including stereotactic radiosurgery) are mostly recommended for patients with ruptured AVMs. Other notable findings were that smaller AVMs, although more likely to present with haemorrhage, did 
not subsequently carry a greater risk of bleeding. This apparent paradox was suggested to be because smaller AVMs are less liable to cause symptoms such as epilepsy before they rupture, implying that they are present in the general population.

The prevailing view of AVMs prior to this study was rather gloomy: 'in the end, most, if not all, patients die of haemorrhage or are completely incapacitated'. The findings of the JNNP study were, thankfully, a lot more optimistic. The risk for neurological impairment was $27 \%$ by 20 years (and related to further intracranial haemorrhage but not baseline features). The risk of developing epilepsy (18\% over 20 years) was highest in those with previous haemorrhage, with an AVM located in the temporal lobe, in women and in patients who were younger at the time of diagnosis (risk of $44 \%$ in those aged $10-19$ years vs $6 \%$ for those over the age of 30 years). All-cause mortality during 20 years of follow-up was 29\%; two-thirds were due to effects of the AVM, mainly related to haemorrhage.

Interestingly, the JNNP paper reported that none of the patients in whom an AVM was found incidentally (about 3\% of the whole population) had intracranial haemorrhage during follow-up. Although the numbers were small, these findings suggest that conservative treatment might be reasonable for unruptured brain AVMs. However, over the years, with technical refinement of neurosurgical and stereotactic radiosurgery, intervention has also been used for unruptured AVMs. Whether unruptured AVMs should be treated remains a major controversy in stroke medicine and neurovascular surgery after the ARUBA (A Randomised trial of Unruptured Brain AVMs) trial found harm from intervention compared with conservative management over $\sim 3$ years of follow-up. ${ }^{7}$ Although the JNNP paper did not directly tackle this question, the uncertainties it resolved on the untreated clinical course of AVMs paved the way for randomised trials to address the ongoing uncertainties about treatment of unruptured AVMs.

Twitter Rustam Al-Shahi Salman @BleedingStroke Funding The authors have not declared a specific grant for this research from any funding agency in the public, commercial or not-for-profit sectors.

Competing interests None declared.

Patient consent for publication Not required.

Provenance and peer review Commissioned; internally peer reviewed.

(c) Author(s) (or their employer(s)) 2020. No commercial re-use. See rights and permissions. Published by BMJ.

Check for updates
To cite Werring DJ, Al-Shahi Salman R. J Neurol Neurosurg Psychiatry 2020;91:1015-1016.

Received 30 April 2020

Accepted 13 May 2020

Published Online First 20 August 2020

J Neurol Neurosurg Psychiatry 2020;91:1015-1016. doi:10.1136/jnnp-2019-322438

\section{ORCID iD}

David J Werring http://orcid.org/0000-0003-2074-1861

\section{REFERENCES}

1 Al-Shahi R, Warlow C. A systematic review of the frequency and prognosis of arteriovenous malformations of the brain in adults. Brain 2001;124:1900-26.

2 Troupp H, Marttila I, Halonen V. Arteriovenous malformations of the brain. Acta Neurochir 1970;22:125-8.

3 Tonnis W, Schiefer W, Walter W. Signs and symptoms of supratentorial arteriovenous aneurysms. J Neurosurg 1958; 15:471-80.

4 Steiner L, Leksell L, Greitz T, et al. Stereotaxic radiosurgery for cerebral arteriovenous malformations. Report of a case. Acta Chir Scand 1972;138:459-64.

5 Crawford PM, West CR, Chadwick DW, et al. Arteriovenous malformations of the brain: natural history in unoperated patients. J Neurol Neurosurg Psychiatry 1986;49:1-10.

6 Kim H, Al-Shahi Salman R, McCulloch CE, et al. Untreated brain arteriovenous malformation: patientlevel meta-analysis of hemorrhage predictors. Neurology 2014;83:590-7.

7 Mohr JP, Parides MK, Stapf C, et al. Medical management with or without Interventional therapy for unruptured brain arteriovenous malformations (ARUBA): a multicentre, non-blinded, randomised trial. Lancet 2014;383:614-21. 